\title{
Analysis of Macedonian Medical Scientific Papers in the Scopus Database
}

\author{
Mirko Spiroski
}

Institute of Immunobiology and Human Genetics, Faculty of Medicine, Ss Cyril and Methodius University of Skopje, Skopje, Republic of Macedonia

\author{
Citation: Spiroski M. Analysis of Macedonian \\ Medical Scientific Papers in the Scopus \\ Database. Maced J Med Sci. 2013 Mar 15; \\ 6(1):5-10. http://dx.doi.org/10.3889/MJMS.1857- \\ 5773.2013.0284. \\ Key words: medical science; Scopus \\ database; citation metrics; h-index; Republic of \\ Macedonia. \\ *Correspondence: Prof. Dr. Mirko Spiroski. \\ Institute of Immunobiology and Human \\ Genetics, Faculty of Medicine, Ss Cyril and \\ Methodius University of Skopje, 1109 Skopje \\ PO Box 60, Republic of Macedonia. E-mail: \\ mspiroski@yahoo.com. \\ Uspiroski@yahoo.com. \\ Received: 28-Feb-2013; Revised: 02-mar- \\ 2013; Accepted: 03-Mar-2013; Online first: \\ 04-Mar-2013 \\ Copyright: (c) 2013 Spiroski M. This is an \\ open-access article distributed under the terms \\ of the Creative Commons Attribution License, \\ which permits unrestricted use, distribution, \\ and reproduction in any medium, provided the \\ original author and source are credited. \\ Competing Interests: The author have \\ declared that no competing interests exist.
}

\begin{abstract}
Aim: The aim of this study was to analyze medical scientific papers in the Republic of Macedonia indexed in the Scopus database.

Material and Methods: A search of the Scopus database was performed on February 23, 2013 in order to identify published papers from the field of medical sciences affiliated with the country Macedonia. A total number of 967 articles were selected for analysis and h-index was calculated from these documents.

Results: The papers were published in a total of 160 journals. The largest number of papers has been published in domestic journals. Two scientists are top two with 59-65 published papers, the next group of eight scientists have published 25-44 papers, and the rest of the authors have published less than 25 papers, each. The published papers have been cited 4380 times (mean citation of 4.5 per paper) with the Hirsh index (h-index) of 27.

Conclusion: An important factor for increasing the quality of the Macedonian medical journals is validation of the published papers in the journals indexed in the Scopus database by the Scientific Board of the Medical Faculty, which is associated with submission and/or defence of PhD theses. Such policy would trigger Editorial Boards of the Macedonian medical journals to improve the quality of their journals and include them in the Scopus database.
\end{abstract}

\section{Introduction}

Scopus is the world's largest abstract and citation database of peer-reviewed literature with smart tools that track, analyze and visualize research. Easy to use and comprehensive, Scopus is designed to quickly find the information researchers' need. Scopus indexes over 20,500 titles from 5,000 publishers worldwide; contains 49 million records, $78 \%$ with abstracts; includes over 5.3 million conference papers; and provides 100\% Medline coverage [1].

Scopus includes a more expanded spectrum of journals than PubMed and Web of Science, and its citation analysis is faster and includes more articles than the citation analysis of Web of Science. On the other hand, the citation analysis that Web of Science presents provides better graphics and is more detailed than the citation analysis of Scopus, probably because Web of Science has been designed with the intention of satisfying users in citation analysis, a field discussed and debated by scientists for decades [2].

Macedonia, officially the Republic of Macedonia, is a country located in the central Balkan Peninsula in Southeast Europe. It is one of the successor states of the former Yugoslavia, from which it declared independence in 1991 [3]. Macedonian medical scientists have published the largest number of papers in domestic medical journals [4]. 
Quality and influence of the Macedonian medical journals are very limited and the pressure of publish or perish force the researchers to publish their scientific results in international journals [5]. Macedonian medical journals lack manuscripts with high quality, do not have regular publication frequency and hence, publish obsolete results. Most of the Macedonian medical journals are not included in the Scopus database [6].

The aim of this study was to analyze medical scientific papers from the Republic of Macedonia included in the Scopus database.

\section{Material and Methods}

A search of the Scopus database was performed on February 23, 2013 in order to identify published papers from the field of medical sciences affiliated with the country Macedonia. From the total of 14 affiliated institutions, four institutions were grouped as medical: Ss Cyril and Methodius University Faculty of Medicine, 60072630; University Clinical Center Skopje, 60072639; Clinic for Children's Diseases Skopje, 60072628; and Institute of Blood Transfusion Skopje, 60072640. A total number of 967 articles were selected for analysis and $\mathrm{h}$ - index was calculated [7, 8].

\section{Results}

The publication of the first papers related to medical sciences from the Republic of Macedonia indexed in Scopus database started in the year 1960 with 13 papers. This number slowly, but steadily was increased and reached its plateau in the years 2008 and 2009 with 89 and 88 published papers, respectively (Fig. 1).

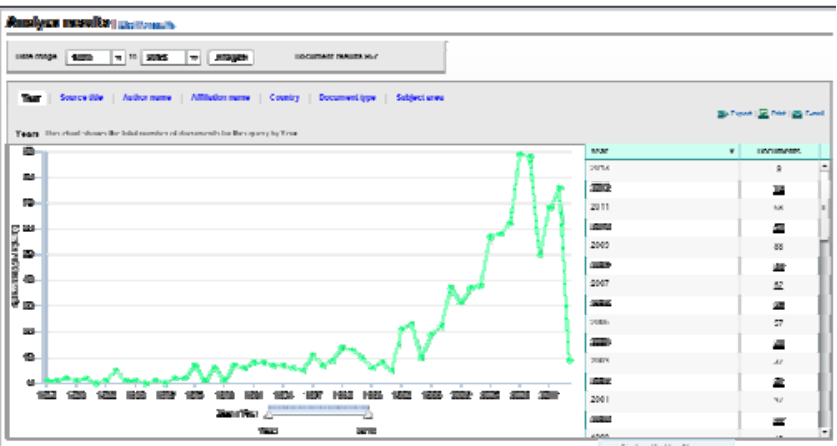

Figure 1: Distribution of published papers from the Republic of Macedonia deposited in the Scopus database

The papers have been published in a total of 160 journals, of which two were Macedonian journals (Macedonian Journal of Medical Sciences and Prilozi), one Balkan journal (Balkan Journal of Medical Genetics) published in Macedonia and the rest of the journals are outside the country (Table 1).
Table 1: Number of papers from Macedonian medical sciences published in different journals of Scopus database.

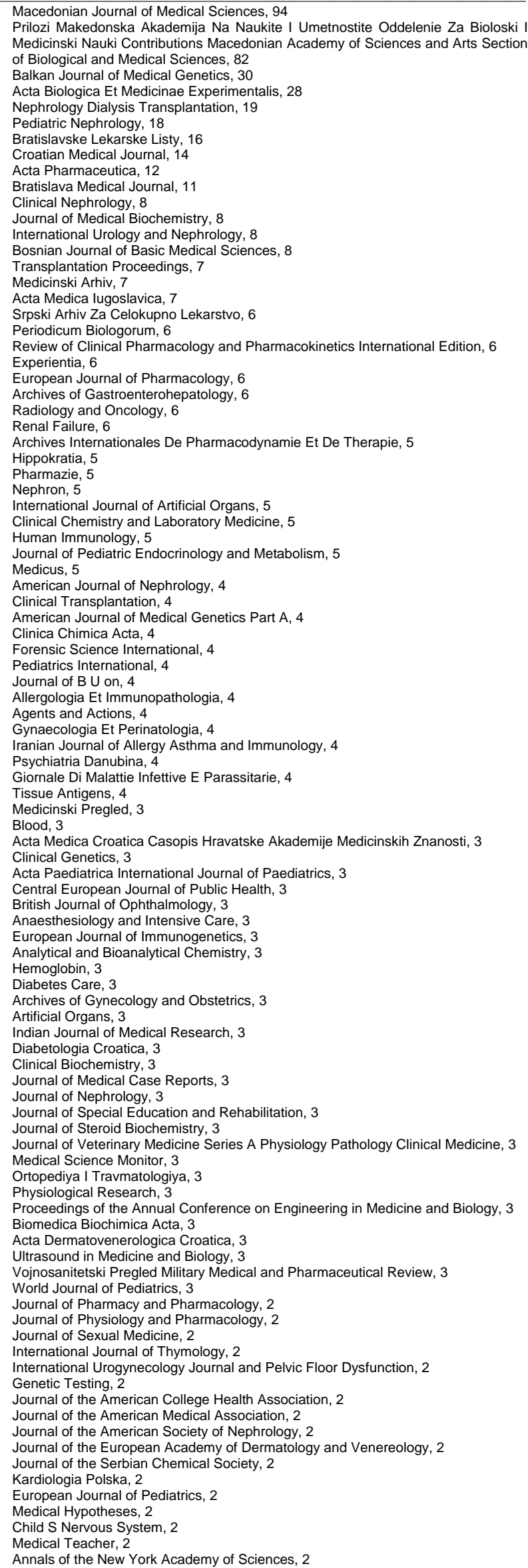

Annals of the New York Academy of Sciences, 2 
97. Annals of Human Genetics, 2

98. Croatica Chemica Acta, 2

99. Proteomics Clinical Applications, 2

100. NDT Plus, 2

01. Annals of Anatomy, 2

102. Angiologia, 2

103. Arhiv Za Higijenu Rada I Toksikologiju, 2

104. Paediatria Croatica,

105. Pathologie Biologie,

106. Pediatric Diabetes, 2

107. Collegium Antropologicum,

108. European Journal of Clinical Investigation, 2

108. European Journal of Clinical Investigation,

109. American Journal of Human

111. Endokrinologya, 2

112. Journal of Chromatography B Analytical Technologies in the Biomedical and Life Sciences, 2

13. Cell Biochemistry and Function, 2

114. Journal of Forensic and Legal Medicine, 2

115. Indian Journal of Pediatrics, 2

116. Giornale Italiano Di Medicina Del Lavoro, 2

117. Acta Facultatis Medicae Naissensis, 2

118. Acta Dermato Venereologica, 2

119. Seminars in Dialysis, 2

20. Skull Base Surgery,

121. FEBS Letters, 2

122. Studies in Health Technology and Informatics, 2

123. Journal of Genetics, 2

124. Cases Journal, 2

125. Turkish Journal of Pediatrics, 2

126. Healthmed, 2

127. Internatiod, 2 Journal of Pharmaceutics, 2

128. Current Medicinal Chemistry, 2

129. Zeitschrift Fur Medizinische Mikrobiologie Und Immunologie, 2

130. Current Drug Targets, 1

31. Child S Brain, 1

132. Chirurgia Maxillofacialis Et Plastica,

33. Chirurgia Narzadow Ruchu I Ortopedia Polska, 1

134. Clinical Application of Immunology, 1

135. Clinical Chemistry, 1

136. Clinical Journal of the American Society of Nephrology,

137. Clinical Laboratory, 1

138. Clinical Pediatrics, 1

139. Clinical Rheumatology, 1

140. Clinical and Transfusion Haematology, 1

141. Cognitive Processing, 1

142. Computational Intelligence and Neuroscience, 1

143. Contributions to Nephrology, 1

144. Cuore, 1

145. Child Abuse and Neglect, 1

146. Dental Materials, 1

147. Diabetes Research and Clinical Practice,

148. Diabetes and Metabolic Syndrome Clinical Research and Reviews, 1

149. Diabetes and Vascular Disease Research, 1

150. Diabetologia Doswiadczalna I Kliniczna, 1

151. Die Naturwissenschaften, 1

52. Digestion, 1

53. Drug Development and Industrial Pharmacy, 1

54. Drugs Under Experimental and Clinical Research,

155. Endocrine Pathology, 1

156. Epileptic Disorders,

157. Epma Journal, 1

158. European Journal of Nuclear Medicine, 1

159. European Journal of Ophthalmology, 1

160. European Journal of Physical and Rehabilitation Medicine, 1

The largest number of papers from the Republic of Macedonia have been published in Macedonian Journal of Medical Sciences (94 papers), followed by Prilozi (82 papers), Balkan Journal of Medical Genetics (30 papers), Acta Biologica Et Medicinae Experimentalis (28 papers). Less than 20 papers per journal have been published in the remaining journals (Fig. 2).

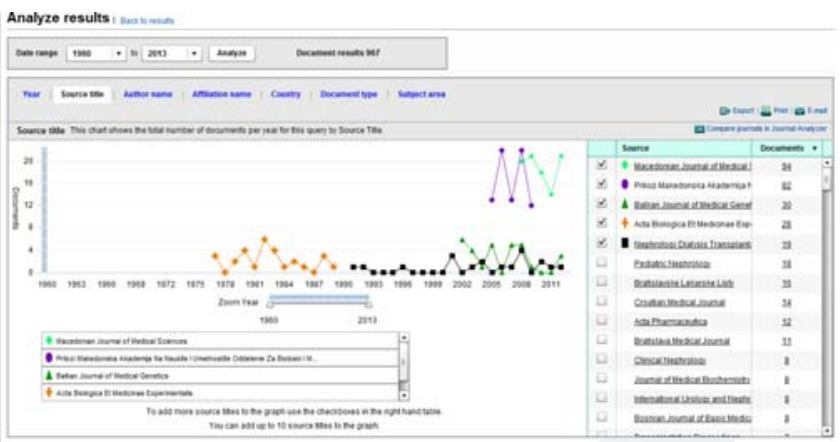

Figure 2: Number of published papers from the Republic of Macedonia in different journals deposited in the Scopus database.
The number of papers published by top ten authors is shown in Figure 3. Two researchers are on the first place, Tasic V (65 papers) and Spiroski M (59 papers). Eighth other authors (Polenakovic M, Gucev Z, Spasovski G, Petlichkovski A, Trajkov D, PopJordanova N, Petrusevska G, and Efremov GD) have published between 40 and 25 papers. The rest of the authors from the Republic of Macedonia have published less than 25 papers each (Fig. 3).

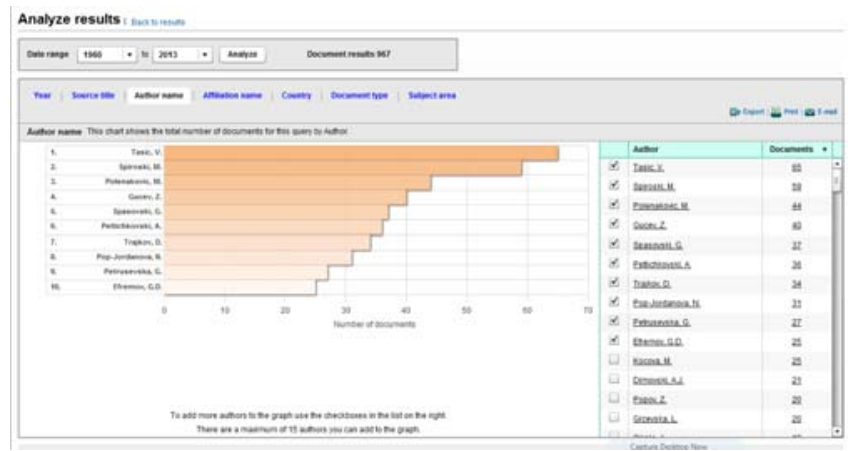

Figure 3: Number of published papers by author name from the Republic of Macedonia in the Scopus database.

About eighty percentage (79.4\%) of the published papers in the Scopus database from the Republic of Macedonia are articles, smaller number of published papers are review articles (5.4\%), undefined $(5.3 \%)$, conference papers $(3.9 \%)$, letters (3.8\%), and others with less than one percentage (Fig. 4).

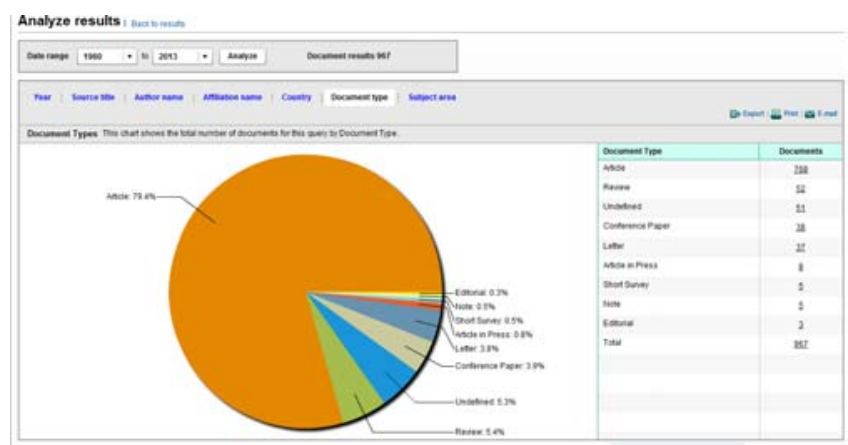

Figure 4: Percentage of document types from the Republic of Macedonia in the Scopus database.

Medicine is represented with $60.3 \%$ in the published papers from the Republic of Macedonia; biochemistry, genetics and molecular biology are represented with 19.1\%; and the other disciplines are represented with lower percentages (about 10\%) (Fig. 5).

The published papers from Macedonian authors deposited in the Scopus database were cited 4380 times with the Hirsh index (h-index) of 27, which means that of the 967 documents considered for the h-index, 27 have been cited at least 27 times. Mean citation of published papers is 4.5 citations per paper (4380 times/967 documents). Scopus does not have complete citation information for articles published before 1996 (Fig. 6). 


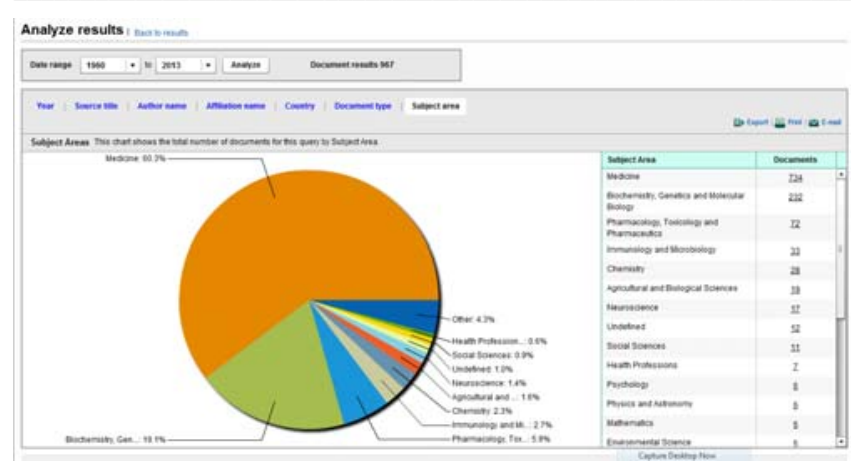

Figure 5: Percentage of subject areas in published papers from the Republic of Macedonia in the Scopus database.

SCImago Journal Rank (SJR) of the two journals from Republic of Macedonia indexed in the Scopus database is shown in Fig. 7. SJR for Macedonian Journal of Chemistry and Chemical Engineering and Macedonian Journal of Medical Sciences was calculated for 2008-2011 year with 0.288 and 0.135 , respectively.

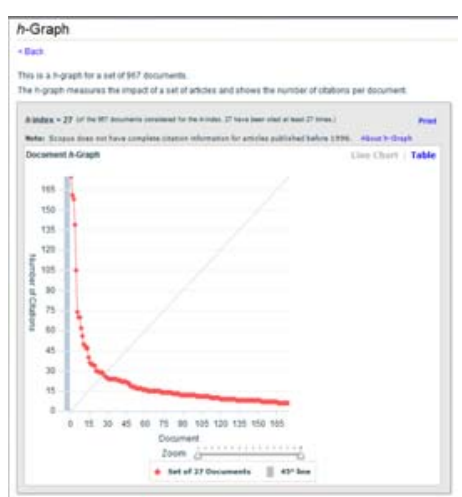

Figure 6: Hirsh index ( $h$ index) of the published papers from the Republic of Macedonia in the Scopus database.

In the Fig. 8 we can see the Source Normalized Impact per Paper (SNIP) of the two journals from Republic of Macedonia indexed in the Scopus database. Macedonian Journal of Chemistry and Chemical Engineering and Macedonian Journal of Medical Sciences for 2008-2011 year have SNIP of 0.829 and 0.168 , respectively.

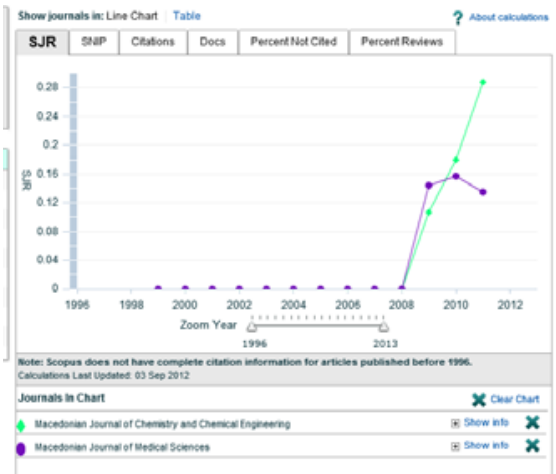

Figure 7: SCImago Journal Rank (SJR) of the two journals from Republic of Macedonia indexed in the Scopus database.

Only one retraction of the Master of Science thesis from Republic of Macedonia has been included in the Scopus database (Retraction: Ana Strezova.
Genotyping of HLA-A, HLA-C and HLA-B Loci with reverse line strip hybridization in Macedonian population and association of HLA class I alleles with spondilitis [MSc thesis]) [9].

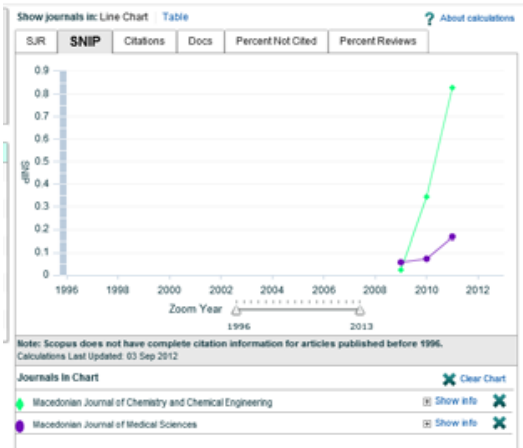

Figure 8: Source Normalized Impact per Paper (SNIP) of the two journals from Republic of Macedonia indexed in the Scopus database.

\section{Discussion}

In this paper we present analysis of Macedonian medical-related documents deposited in the Scopus database. The largest number of published papers related to medical sciences from the Republic of Macedonia was noticed in the years 2008 and 2009. The papers were published in a total of 160 journals, of which two were Macedonian journals, one Balkan journal published in Macedonia, and the rest of the journals were published outside the country. The largest number of published papers from the Republic of Macedonia is in journals published at home (Macedonian Journal of Medical Sciences, Prilozi, and Balkan Journal of Medical Genetics).

The top two scientists are represented with 59-65 published papers, the next group of eight scientists have published $25-44$ papers, and the rest of the authors have published less than 25 papers, each. Most of the published papers in the Scopus database from the Republic of Macedonia are articles. Medicine is represented with more than a half of published papers, but biochemistry, genetics and molecular biology are also represented in one fifth of the total number. The published papers were cited 4380 times (mean citation of 4.5 per paper) with the Hirsh index (h-index) of 27. Only one retraction of the Master of Science thesis from the Republic of Macedonia has been recorded in the Scopus database [9].

Medical journals published in the Republic of Macedonia since the Second World War were analysed in an earlier study [4]. A total of 37 journals, either in printed or electronic version, were included in the study. Data referring to 14 titles of journals were obtained from COBIB.MK, but unfortunately only two of them are indexed in Scopus database (Macedonian Journal of Medical Sciences and Prilozi). It was concluded that our medical journals should become a 
school on how medical problems are treated and how to prepare a paper for medical journals. However, the authors concluded that it is necessary to reach the European level of basic and clinical research in medical science in the Republic of Macedonia [4].

We have published a series of reviews in MJMS where we presented the state of the current scientific influence of Macedonian medical journals, their inclusion in medical databases and consequently the influence of Macedonian medical scientists in the world. Macedonian biomedical scientists included in the BiomedExperts Database contribute $0.006 \%$ in this database [10]. We found very limited scientific influence of Macedonian medical journals according to the internationally recognized citation metrics indexes because only one journal (Prilozi) was currently indexed in PubMed and Google Scholar [11]. The SClmago database was also used for analysis of country rank, journal rank and $\mathrm{H}$-index in the field of medicine in the Republic of Macedonia. These parameters are in the range of the other former Yugoslav countries, but again only Prilozi and Macedonian Journal of Medical Sciences are included in this database [6]. Mukaetova-Ladinska E and Korneti-Pekevska $K$ [12] emphasized the fact that undergraduate and postgraduate course organizers have to engage the students as early as possible in the academic career. On the other hand, the academic staff should organize good research in our institutions, and should strive to publish high peerreviewed papers [12].

Mean citation of published papers from Macedonian authors deposited in the Scopus database is 4.5 citations per paper (4380 times/967 documents) which is fairly good result. The Hirsh index (h-index) of 27 for all published papers by Macedonian authors indexed in Scopus is low and should be increased. The biggest $\mathrm{H}$-index of 10 , for the period between 2007 and 2008, in the Republic of Macedonia was found for nephrology subject category, followed by medicine (miscellaneous) with $\mathrm{H}$-index of 7 , haematology and endocrinology, diabetes and metabolism with $\mathrm{H}$-index of 6 , transplantation, oncology and pathology and forensic medicine with $\mathrm{H}$-index of 5 [6].

Publication ethics established by the Editorial Boards of Macedonian medical journals is in the very early stage with very rare use of tools for checking similarities between submitted manuscripts and published papers. There is only one retraction published in Scopus database [9], but there are ten papers with very big similarities deposited in Deja vu database from the medical scientists of the Republic of Macedonia [13]. Members of Editorial Boards should learn how to use tools for investigation of similarities and ethical committees should check all kinds of unethical behaviours of authors.

The Scopus Journal Analyzer provides a measure of journal performance and enables you to compare up to 10 journals simultaneously, back to
1996. The Scopus Journal Analyzer includes 2 journal metrics: SJR (SCImago Journal Rank) is a prestige measure based on the idea that all citations are not created equal. With SJR, the subject field, quality and reputation have a direct effect on the value of a citation [14] and SNIP (Source Normalized Impact per Paper) measures citation impact by weighting citations based on the total number of citations in a specific subject field. The impact of a single citation is given higher value in subject areas where citations are less likely, and vice versa [15, 16]. SJR and SNIPS for Macedonian Journal of Chemistry and Chemical Engineering and Macedonian Journal of Medical Sciences are indicators for the quality of these journals.

In my opinion, another important factor for increasing the quality of the Macedonian medical journals is validation of the published papers in the journals indexed in Scopus by the Deans' Office/Scientific Board of the Medical Faculty, which is associated with submission and/or defence of $\mathrm{PhD}$ theses. Such policy would trigger Editorial Boards of the Macedonian medical journals to improve the quality of their journals and include them in the Scopus database.

\section{References}

1. Bakkalbasi N, Bauer K, Glover J, Wang L. Three options for citation tracking: Google Scholar, Scopus and Web of Science. Biomed Digit Libr. 2006;3:7.

2. Falagas ME, Pitsouni EI, Malietzis GA, Pappas G. Comparison of PubMed, Scopus, Web of Science, and Google Scholar: strengths and weaknesses. FASEB J. 2008;22(2):338-42.

3. Daskalovski Z. Democratic consolidation and the 'stateness' problem: The case of Macedonia. The Global Review of Ethnopolitics, 2004;3.2: 52-66.

4. Polenakovic M, Danevska L. Medical journals in the Republic of Macedonia after the Second World War. Prilozi. 2011;32(2):11-31.

5. Macedonian Journal of Medical Sciences. Macedonian International Medical Publications Indexed in PubMed in 2011. Maced J Med Sci. 2012; 5(2):222-252.

6. Spiroski M. Country Rank, Journal Rank and H-Index in the Field of Medicine in the Republic of Macedonia (1996-2008) Using Data from SCImago. Maced J Med Sci. 2010;3(2):99108.

7. Burnham JF. Scopus database: a review. Biomed Digit Libr. 2006;3:1-8

8. Hirsch JE. Does the $\mathrm{H}$ index have predictive power? Proc Natl Acad Sci U S A. 2007;104(49):19193-8.

9. Spiroski M. Retraction: Ana Strezova. Genotyping of HLA-A, HLA-C and HLA-B Loci with Reverse Line Strip Hybridization in Macedonian Population and Association of HLA Class I Alleles with Spondilitis [MSc thesis]. Maced J Med Sci. 2010; 3(2):188-191.

10. Spiroski M. Macedonian biomedical scientists are not adequately represented in BiomedExperts database. Maced $\mathrm{J}$ Med Sci. 2008; 1(1):13-17.

11. Spiroski M, Gogusev J. Macedonian Medical Journals Have Very Limited Scientific Influence. Maced J Med Sci. 2008; 1(2):10-16. 
12. Mukaetova-Ladinska EB, Korneti-Pekevska K. A Macedonian Biomedical Science: Current Standing and Suggestions for Improvement. Maced J Med Sci. 2010;3(1):5-8.

13. Spiroski M. Déjà vu: A report of highly similar citations in the Biomedical scientific literature from the Republic of Macedonia. Maced J Med Sci. 2009;2:107-114.

14. González-Pereira B, Guerrero-Bote V, Moya-Anegon F. The SJR indicator: A new indicator of journals' scientific prestige. arXiv preprint arXiv. 2009;0912.4141.

15. Moed HF. Measuring contextual citation impact of scientific journals. Journal of Informetrics. 2010; 4(3), 265-277.

16. Moed HF, Colledge L, et al. Citation-based metrics are appropriate tools in journal assessment provided that they are accurate and used in an informed way. Scientometrics. 2012; 92(2): 367-376. 